\title{
Reliability Improvement in III-V Concentrator Solar Cells by Means of Perimeter Protection
}

\author{
José R. González ${ }^{1}$, Manuel Vázquez ${ }^{1,2}$, Neftalí Núñez ${ }^{1,2}$, Carlos Algora $^{1}$ and \\ Pilar Espinet ${ }^{1}$
}

\author{
${ }^{1}$ INSTITUTO DE ENERGÍA SOLAR - UNIVERSIDAD POLITÉCNICA DE MADRID \\ Avda. Complutense s/n, Ciudad Universitaria \\ 28040 Madrid (Spain) \\ ${ }^{2}$ EUIT DE TELECOMUNICACIÓN - UNIVERSIDAD POLITÉCNICA DE MADRID
}

\begin{abstract}
This paper presents the evolution in the strategy to assess the reliability of III-V solar cells and a new thermal ageing test carried out over GaAs single junction solar cells at three different temperatures (130, 150 and $170^{\circ} \mathrm{C}$ ). The perimeter of the solar cells has been protected with silicone, which seems to be an effective way of enhancing the reliability of the solar cells. A preliminary analysis of the results indicates a mean time to failure (MTTF) one order of magnitude larger than the one obtained in a previous thermal test with the perimeter uncoated.
\end{abstract}

Keywords: Reliability, Degradation, Qualification

PACS: 88.40.-j; 88.40.ff; 88.40.H; 88.05.-b

\section{INTRODUCTION}

Photovoltaic concentration has proven to be an effective means for reducing the costs of photovoltaic electricity production [1]. In recent years, significant advances have been made in the field of III-V highconcentrator solar cells, achieving peak efficiencies of $32.6 \%$ at 1000 suns for a dual junction solar cell [2] and $41.6 \%$ at 236 suns for a triple junction solar cell [3].

These satisfactory results have crystallized into the first commercial ventures of concentration photovoltaic systems based on III-V solar cells. Representative companies can be found around the world [4][5][6][7][8][9][10][11][12]. At present, there is a total amount of more than $17 \mathrm{MW}$ of concentrator photovoltaic (CPV) systems installed in the world, from which more than $4 \mathrm{MW}$ are based on III-V solar cells [13].

Silicon flat modules are reliable systems that have been deployed in field applications for more than 30 years. Nowadays, silicon manufacturers' warranties usually extend to 25 years of use, and are expected to increase to 30 years in the near future [14]. If CPV systems are to compete with silicon flat modules, they must be covered by similarly extensive warranties. Before such extensive warranties may be issued, however, the reliability of these devices must first be confirmed.

The CPV community, aware of this situation, has made an important effort in the last years to solve this problem. As a result of this, a couple a years ago, a qualification standard for CPV modules and assemblies saw the light [15]. However, even though qualification and degradation are of great importance, it must be kept in mind that reliability is a completely different issue. Reliability tests should be directed not only to determine how long devices are going to live, but the way in which these devices are going to live. In other words, reliability is also interesting in knowing the probability distribution of failure in nominal conditions of operation

First studies have been carried out in an effort to characterize the reliability of III-V concentrator solar cells. In view of the similarities between some type of III-V concentrator solar cells and light emitting diodes (LEDs), the lifespan of CPV solar cells was predicted to be characterized by, at least, a mean time to failure (MTTF) of up to $10^{5}$ hours [16] (equivalent to 34 years assuming an average of 8 hours of operation per day). This lowest MTTF value prediction has been recently corroborated by an step-stress accelerated ageing test in which a functional MTTF persisted longer than 69 years with a 90\% unilateral confidence interval [17]. 
The failure analysis showed that the uncoated solar cells failed because of perimeter shunting.

This work presents a new test which has been carried out over GaAs single junction solar cells. Among other improvements with respect to the test carried out in [17], these cells have been covered with a silicone in order to protect the perimeter, as this was the location of the failure in that previous accelerated ageing test. First results are already available showing a power degradation of less than $2.5 \%$ after a testing time extrapolated to $65^{\circ} \mathrm{C}$ of about $3.92 \cdot 10^{6} \mathrm{~h}$.

\section{STRATEGY}

A working plan has been defined to carry out the reliability assessment on concentrator solar cells as FIGURE 1 shows. This plan consists of real time tests and accelerated ageing tests. The accelerated tests allow to shorten the time to evaluate the reliability of a device; the real time tests allow to determine if the stress factor introduces failure modes that would never happen in real operation.

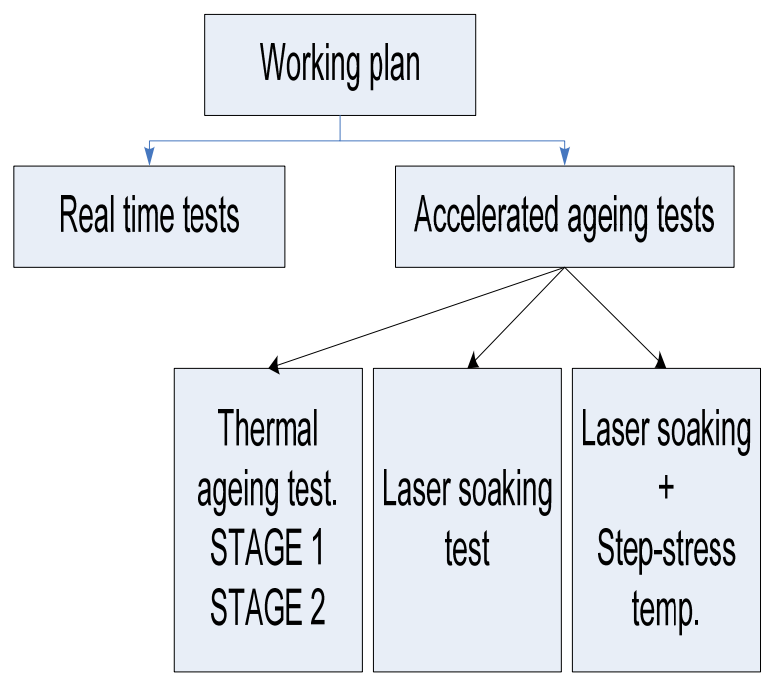

FIGURE 1: Working plan for assessing the reliability.

Considering the accelerated ageing test, the step-stress temperature ageing test (stage 1) and laser soaking (see FIGURE 1) have been already carried out over GaAs single junction cells. In a next stage, we will combine both tests at the same time to evaluate the whole action of increasing light and temperature. In a short future these tests will be done over double and triple junction solar cells. The test presented here, is a new attempt to overcome the failure modes encountered in the first temperature ageing test.

The first set of reliability studies have been conducted on bare III-V concentrator solar cells, but the reliability of the module has not yet been determined.
Therefore we have also focused our testing working plan in assessing the reliability of the module, not only to gain insight into this point, but also to determine the real time evolution of the device. We have developed a statistical model for assessing the reliability of a photovoltaic module based on degradation data. The mentioned model has been applied to an ad hoc manufactured CPV module, in which independent electrical access was provided to each receiver in order to evaluate the performance over time without the masking effects that a series or parallel connection configuration may introduce [18]. FIGURE 2 shows the tracked installed on the flat-roof of the Instituto de Energía Solar - Universidad Politécnica de Madrid (IES-UPM).

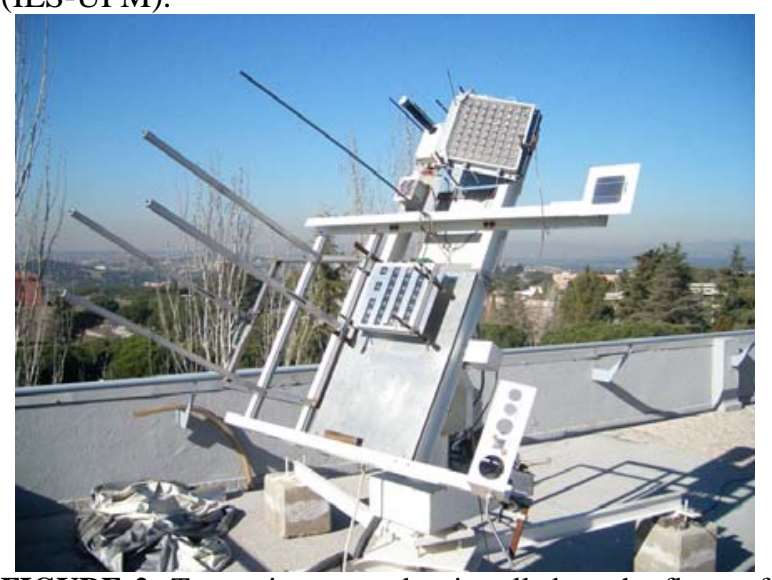

FIGURE 2: Two-axis sun tracker installed on the flat roof of the Instituto de Energía Solar - Universidad Politécnica de Madrid (IES-UPM).

\section{EXPERIMENTAL}

The test carried out in [17] revealed some technological situations that were responsible for the failure. Small size high concentrator solar cells (about $1 \mathrm{~mm}^{2}$ ) present a high perimeter/area ratio. It is well known that one of the most important defects that can be found in a crystal is the free surface, because of dangling bonds and surface reconstruction. For this reason the exposed perimeter is an ideal place for the chemical reaction with environmental agents to be enhanced as well as a priority place for defects to migrate. One of the main purposes of this stage 2 in temperature ageing test is aimed at overcoming this situation.

The assembly of the cells used in this test features the following characteristics:

1) Encapsulation on Direct Bonded Copper (DBC) substrates to increase the thermal dissipation.

2) Encapsulated cells are attached to an aluminum box with a thermal-conductive adhesive.

3) Cells were covered with silicone, to simulate the real situation of a cell inside a secondary optics in 
a concentrator, which in addition protects the cells, in particular their perimeter.

FIGURE 3 shows an image of the solar cells inside the climatic chamber, in which some of the previous features can be identified. The boxes the cells were attached to were covered with a glass to guarantee a flat surface and avoid the curvature caused by the surface tension in the silicone, allowing thus all the cells to be measured under illumination in the same conditions. FIGURE 4 shows a detail of the setup in which climatic chambers can be seen.

Working conditions were simulated by forward biasing the solar cells at the same current level their perimeter would handle at two concentrations: 700 and 1050 suns.

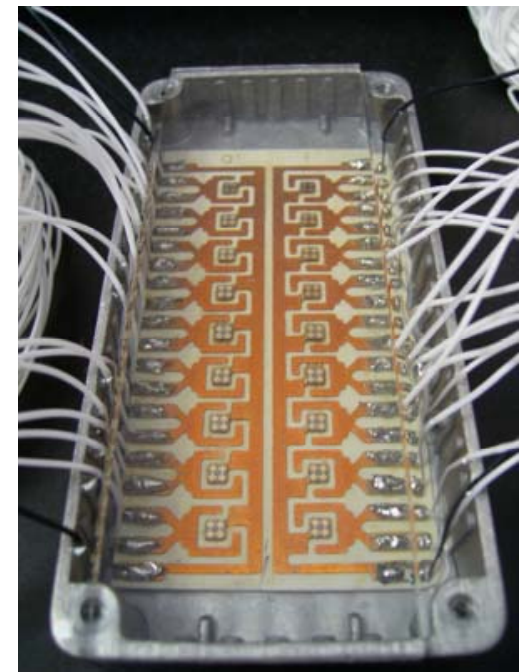

FIGURE 3: solar cells encapsulated on a DBC substrate and covered with silicone. The caption shows the wiring inside the climatic chamber before the beginning of the test.

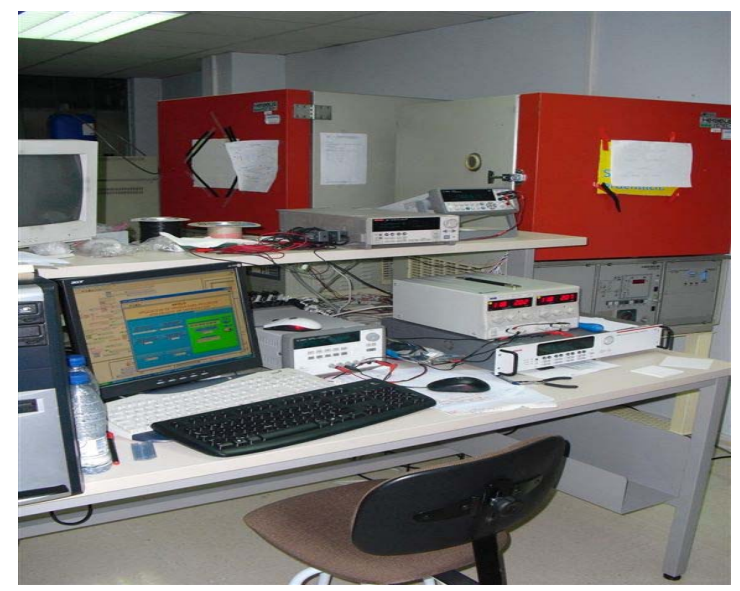

FIGURE 4: experimental setup with the climatic chambers while the test was ongoing.

\section{RESULTS}

The power of every solar cell has been normalized to its initial value, providing an assessment independent of the initial dispersion and, after 4000 hours power, losses in the range from 2 to $5 \%$ have been stated. FIGURE 5, shows the normalized power evolution for one representative cell at $150^{\circ} \mathrm{C}$, in which the power loss is approximately $2.7 \%$ after 4000 hours.

In the previous thermal ageing test, failure was defined as a power loss of $10 \%$ with respect to its original value [17]. In this test, this value has revealed to be too high and a new value of $2.5 \%$ seems to be more suitable according to the power evolution of the cells tested. As the solar cells have been measured in darkness, inside a climatic chamber, we have used a method to extrapolate the illumination I-V curve from the dark one [19]. FIGURE 5 shows a graph of the normalized power evolution for one representative cell tested at $150^{\circ} \mathrm{C}$.

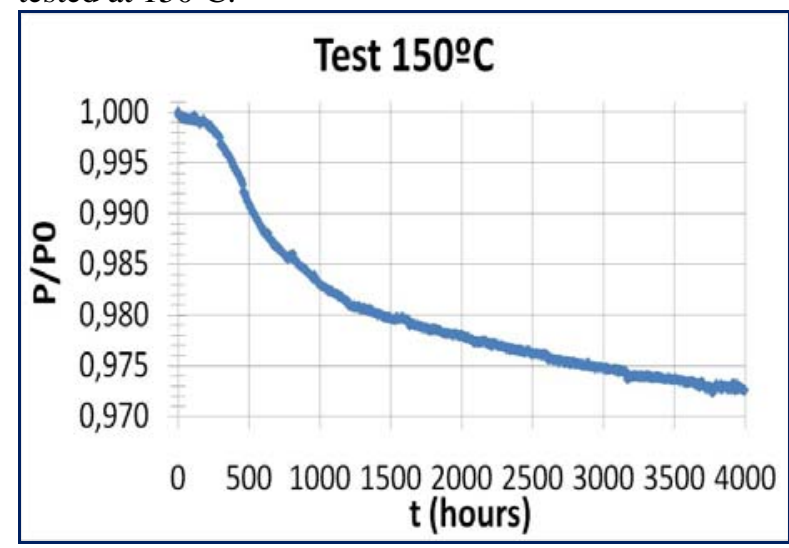

FIGURE 5: normalized power evolution for one representative cell at $150^{\circ} \mathrm{C}$. After 4000 hours the power loss is approximately $2.7 \%$.

Assuming the failure at a power loss of $2.5 \%$, and taking into account low degradation rate for such a long test, a preliminary analysis of the results indicates a value of the MTTF one order of magnitude larger than the one obtained in the thermal test-stage 1, with the perimeter uncoated $\left(2.05 \cdot 10^{5} \mathrm{~h}\right.$, i.e. about 70 years assuming 8 hours of daily working on average in a year [17]).

To determine the cause of failure, the dark I-V curves simulated with a software tool based on a distributed 3D model [20]. FIGURE 6 shows the dark I$\mathrm{V}$ curves before and after the test for one of the cells tested at $150^{\circ} \mathrm{C}$. The dot-line corresponds to the experimental curve and the continuous one to the simulated curve. The results of the simulation show that the cells experience an increase of four times in the perimeter recombination current density $\left(J_{02, p e r}\right)$, from $2 \cdot 10^{-12}$ to $4 \cdot 10^{-1} \mathrm{~A} / \mathrm{cm}$. 


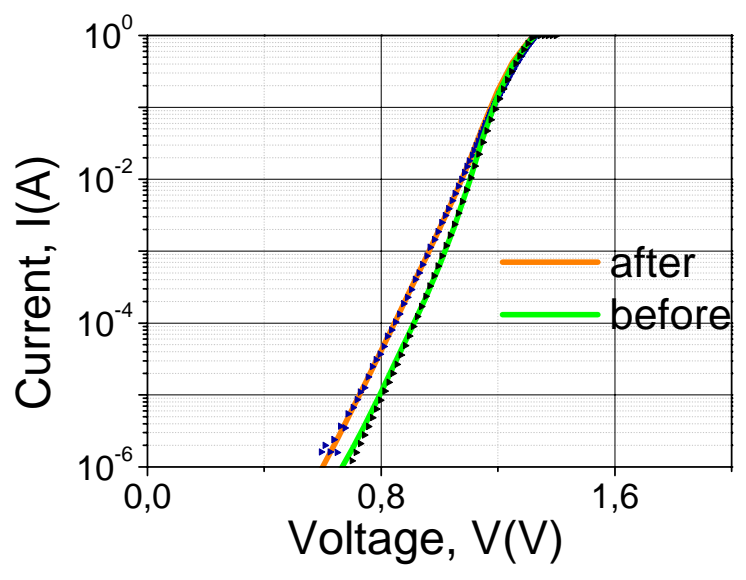

FIGURE 6: dark I-V curves before and after the test for one of the cells tested at $150^{\circ} \mathrm{C}$. The dot-line corresponds to the experimental curve and the continuous one to the simulated curve.

\section{SUMMARY AND CONCLUSIONS}

This paper presents a new thermal ageing test which has been carried out over GaAs single junction solar cells for simplicity but the protocols defined here and, probably, the results, can be extended to multijunction cells. Three different groups of eighteen cells have been subjected to three different temperatures, i.e. 130,150 and $170^{\circ} \mathrm{C}$.

Main conclusions are:

1) The degradation trend is the same for the three groups of cells tested.

2) A new failure criterion has been assumed in this test, lowering the power loss from 10[17] to $2.5 \%$.

3) The low degradation in such a long test suggest a value of the MTTF one order the magnitude larger than the one obtained in the thermal test-stage 1 , with the perimeter uncoated $\left(2.05 \cdot 10^{5} \mathrm{~h}\right.$, aprox. 70 years [17]).

4) The results of the simulation show that the cells experience an increase of four times in the perimeter recombination current density $\left(J_{02, \text { per }}\right)$, from $2 \cdot 10^{-12}$ to $4 \cdot 10^{-1} \mathrm{~A} / \mathrm{cm}$. Therefore, the perimeter protection seems to be a good way of enhancing the reliability of the solar cells.

\section{ACKNOWLEDGMENTS}

This work has been supported by the Spanish Ministerio de Educación y Ciencia with the CONSOLIDER-INGENIO 2010 program by means of the GENESIS FV project (CSD2006-004). The Spanish Ministerio de Ciencia e Innovación has also contributed with the SIGMASOLES project (PSS440000-2009-30) and with the project with reference TEC2008-01226 as well as the Comunidad de Madrid under the NUMANCIA II programme (S2009/ENE1477). The European Union has also contributed by means of The European Found for Regional Development (FEDER).

\section{REFERENCES}

[1] J. Luther, A. Luque, A. W. Bett, F. Dimroth, H. Lerchenmüller, G. Sala and C. Algora, "Concentration photovoltaics for highest effciencies and cost reduction”, 20th European Photovoltaic Solar Energy Conference, Barcelona, Spain 2005

[2] C. Algora, I. Rey-Stolle, I. García, B. Galiana, P. Espinet, M. Baudrit, E. Barrigon, J. R González and J. Bautista., "A dual junction solar cell with an efficiency of $32.6 \%$ at 1000 suns and $31.0 \%$ at 3000 suns", 5th International Conference for the Generation of Electricity, Palm Desert, Nov. 2008, Proceedings (ISBN: 978-0-615-29119-2).

[3] R.King et al. "Band-Gap-Engineered Architectures for HighEfficiency Multijunction Concentrator Solar Cells”, 24th European Phtovolt. Solar Energy Conf. and Exhibition, Hamburg, September, 2009.

[4]On the Website: www.solarsystems.com.au

[5] On the Website: www.solfocus.com

[6] On the Website: www.isofoton.com

[7] On the Website: www.concentrixsolar.de

[8] On the Website: www.daido.co.jp

[9] On the Website: www.entechsolar.com

[10] On the Website: http://www.power-spar.com

[11] On the Website: http://www.pyronsolar.com

[12] On the Website: http://www.sol3g.com

[13] F. Rubio, P. Banda, "Concentrated photovoltaics: the path to high efficiency”. PVI02-08_6. Published in PVtech magazine fourth Quarter 2008

[14] J. H. Wohlgemuth, D. W. Cunningham, A. M. Nguyen, J. Miller, "Long term reliability of PV module." 20th European Photovoltaic Solar Energy Conference, Barcelona, Spain, 2005; 1942-1946.

[15] IEC62108: "Concentrator photovoltaic (CPV) modules and assemblies - Design qualification and type approval”, Ed.1.

[16] M. Vázquez, C. Algora, I. Rey-Stolle, J. R. González. III-V concentrator solar cell reliability prediction based on quantitative LED reliability data. Progress in Photovoltaics: Res Appl 2007;15(6).

[17] J. R. González, M. Vázquez, N. Núñez, C. Algora, I. Rey-Stolle and B. Galiana, "Reliability Analysis of Temperature Step-stress Tests on III-V High Concentrator Solar Cells". Microelectronics Reliability 49 (2009), pp. 673-680.

[18] J. R. González, M. Vázquez, C. Algora and N. Núñez, "Realtime reliability test for a CPV module based on a power degradation model”. Progress in Photovoltaics: Research and Applications

[19] Antón I, Sala G, Heasman K, Kern R, Bruton TM. Performance prediction of concentrator solar cells and modules from dark IV characteristics. Prog Photovolt: Res Appl 2003;11:165-78.

[20] B. Galiana, C. Algora, I. Rey-Stolle, and I. García. A 3-D model for concentrator solar cells based on distributed circuit units. IEEE Transactions on Electron Devices, pages 25522558, 2005 